\title{
Infection par le virus d'Epstein-Barr associée à une cholécystite alithiasique aiguë chez une femme de 20 ans
}

\author{
Hiroaki Nakagawa MD, Yasushi Miyata MD PhD
}

E Citation : CMAJ 2021 May 10;193:E696. doi : 10.1503/cmaj.202043-f

Voir la version anglaise de l'article ici : www.cmaj.ca/lookup/doi/10.1503/cmaj.202043
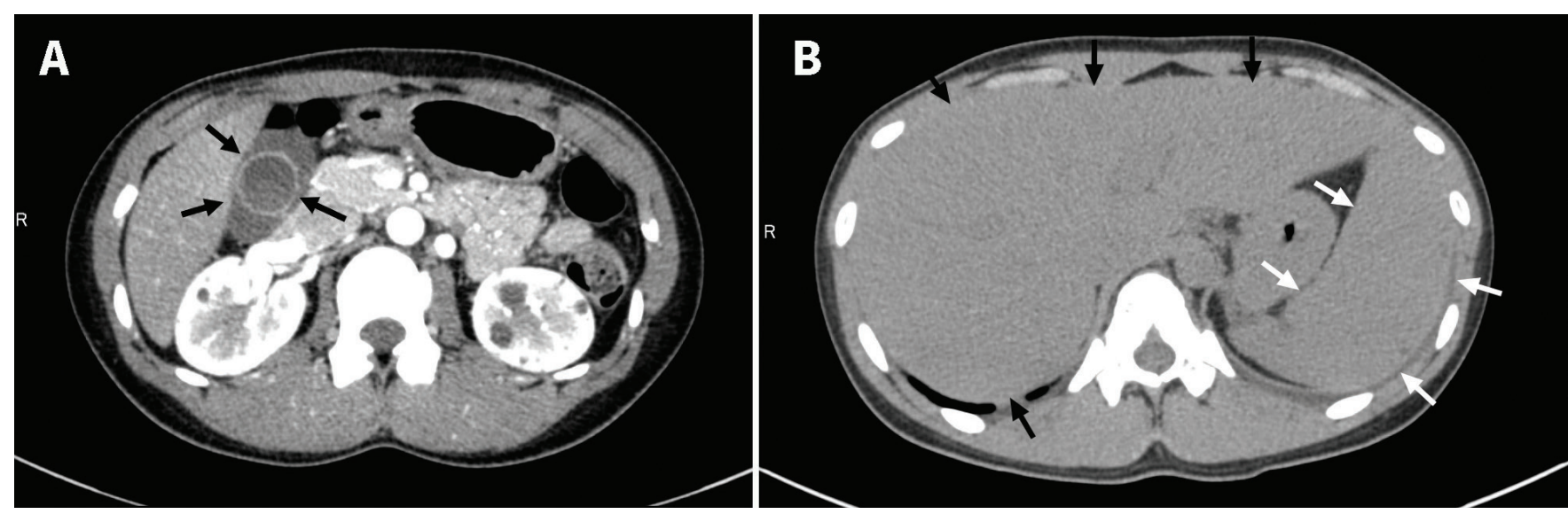

Figure 1 : Tomodensitométrie abdominale chez une femme de 20 ans présentant une douleur persistante au quadrant supérieur droit, montrant (A) une vésicule biliaire hypertrophiée accompagnée d'un épaississement de la paroi et une accumulation de liquide péricholécystique (flèches noires) et (B) une hépatosplénomégalie légère (les flèches blanches montrent la rate hypertrophiée, les flèches noires montrent le foie hypertrophié). Aucun calcul n'est visible dans la vésicule biliaire ou le canal cholédoque.

$\mathbf{U}$ ne femme de 20 ans sans antécédents médicaux importants s'est présentée à notre consultation externe avec un mal de gorge, de la toux et une douleur persistante au quadrant supérieur droit aggravée par le mouvement ou une respiration profonde et perdurant depuis 7 jours. L'examen physique a révélé une inflammation des amygdales, une sensibilité bilatérale et une enflure des nœuds lymphoïdes cervicaux postérieurs, une sensibilité au quadrant supérieur droit et un signe de Murphy positif. Les analyses sanguines ont révélé une leucocytose (numérotation de 17,0 [normale 5,0-8,0] $\times 10^{9} / \mathrm{L}$, $48 \%$ de lymphocytes, aucun lymphocyte atypique) et des taux d'enzymes hépatiques élevés (aspartate aminotransférase de 201 [normale 13-33] IU/L, alanine aminotransaminase de 190 [normale 6-27] IU/L, phosphatase alcaline de 433 [normale 115359] IU/L et $\gamma$-glutamyltransférase de 132 [normale 10-47] IU/L). La tomodensitométrie abdominale (TDM) a révélé une vésicule biliaire hypertrophiée présentant un épaississement de la paroi et une accumulation de liquide péricholécystique (figure $1 \mathrm{~A}$ ) et une hépatosplénomégalie (figure 1B). Aucun calcul n'a été observé dans la vésicule biliaire, le canal cystique et le canal cholédoque, ce dernier n'étant pas dilaté (diamètre de $6,0 \mathrm{~mm}$ ). Sur la base de ces observations, nous avons soupçonné une mononucléose infectieuse accompagnée d'une cholécystite alithiasique aiguë. La patiente a obtenu un résultat positif au test de dépistage de l'immunoglobuline (Ig) M et des anticorps IgG associés à la capside virale de l'antigène du virus d'Epstein-Barr et un résultat négatif aux anticorps pour l'antigène nucléaire du virus d'EpsteinBarr, confirmant le diagnostic. Les symptômes se sont résorbés dans les 7 jours suivants le traitement de ces derniers.

La cholécystite alithiasique aiguë est caractérisée par un épaississement de la paroi de la vésicule biliaire, une hypertrophie de cette dernière, une accumulation de liquide péricholécystique et l'absence de calculs, confirmée à l'échographie ou à la tomodensitométrie ${ }^{1}$. Elle est observée, quoique peu fréquemment, chez les patients dont l'état de santé est critique en raison d'un traumatisme, d'un choc ou de brûlures. Dans ces cas, le taux de mortalité est élevé et le traitement exige des antibiotiques, une cholécystostomie ou une cholécystectomie ${ }^{1}$. La cholécystite alithiasique aiguë se manifeste 
aussi en association avec certaines infections virales, dont le virus d'Epstein-Barr, le cytomégalovirus et le virus de la dengue ${ }^{1}$. On croit que la cholécystite alithiasique aiguë associée au virus d'Epstein-Barr est causée par une infiltration virale directe de la muqueuse et une cholestase de la vésicule biliaire ${ }^{2}$. L'âge moyen du déclenchement de la maladie est 17 ans et elle survient surtout chez les femmes. La cholécystite alithiasique aiguë associée au virus d'Epstein-Barr, contrairement à la cholécystite alithiasique aiguë associée à d'autres causes, présente un bon pronostic. La plupart des cas se résorbent de façon spontanée, sans antibiotiques ni intervention chirurgicale ${ }^{3}$.

\section{Références}

1. Huffman JL, Schenker S. Acute acalculous cholecystitis: a review. Clin Gastroenterol Hepatol 2010;8:15-22.

2. Branco L, Vieira M, Couto C, et al. Acute acalculous cholecystitis by EpsteinBarr virus infection: a rare association. Infect Dis Rep 2015;7:6184.

3. Kottanattu L, Lava SAG, Helbling R, et al. Pancreatitis and cholecystitis in primary acute symptomatic Epstein-Barr virus infection-systematic review of the literature. J Clin Virol 2016;82:51-5.

Intérêts concurrents : Aucun déclaré.

Cet article a été révisé par des pairs.

Les auteurs ont obtenu le consentement de la patiente.

Affiliations : Division de médecine générale (Nakagawa) et Département de soins primaires et de santé communautaire (Miyata), École de médecine de l'Université médicale Aichi, Nagakute, Japon.

Propriété intellectuelle du contenu : Il s'agit d'un article en libre accès distribué conformément aux modalités de la licence Creative Commons Attribution (CC BY-NC-ND 4.0), qui permet l'utilisation, la diffusion et la reproduction de tout médium à la condition que la publication originale soit adéquatement citée, que l'utilisation se fasse à des fins non commerciales (c.-à-d., recherche ou éducation) et qu'aucune modification ni adaptation n'y soit apportée. Voir : https://creativecommons.org/licenses/by-nc-nd/4.0/deed.fr.

Correspondance : Hiroaki Nakagawa, hraknakagawa@gmail.com

Les images cliniques sont choisies pour leur caractère particulièrement intéressant, classique ou impressionnant. Toute soumission d'image de haute résolution claire et bien identifiée doit être accompagnée d'une légende aux fins de publication. On demande aussi une brève explication (300 mots maximum) de la portée éducative des images, et des références minimales. Le consentement écrit du patient au regard de la publication doit être obtenu avant la soumission. 